\title{
Deaf Individuals’ Bilingual Abilities: American Sign Language Proficiency, Reading Skills, and Family Characteristics
}

\author{
Brittany L. Freel $^{1,3}$, M. Diane Clark ${ }^{1,2}$, Melissa L. Anderson ${ }^{1,2}$, Gizelle L. Gilbert ${ }^{1,2}$, \\ Millicent M. Musyoka ${ }^{1,2}$, Peter C. Hauser ${ }^{1,3}$ \\ ${ }^{1}$ Science of Learning Center on Visual Language and Visual Learning, Washington, DC, USA; \\ ${ }^{2}$ Gallaudet University, Washington, DC, USA; \\ ${ }^{3}$ National Technical Institute of the Deaf / Rochester Institute of Technology, Rochester, NY, USA. \\ Email: diane.clark@gallaudet.edu \\ Received October 11 $1^{\text {th }}, 2010$; revised November $2^{\text {nd }}, 2010$; accepted December $10^{\text {th }}, 2010$.
}

\begin{abstract}
The current study investigated the bilingual abilities of 55 Deaf individuals, examining both American Sign Language (ASL) competency and English reading skills. Results revealed a positive relationship between ASL competency and English skills, with highly competent signers scoring higher on a measure of reading comprehension. Additionally, family characteristics (e.g., parental education level, family hearing status) were entered into the analysis to ascertain their effect on Deaf individuals' bilingual abilities. The findings support the theory that competency in ASL may serve as a bridge to the acquisition of English print. Moreover, the findings provide support for the critical period hypothesis for first language acquisition and its later impact on other cognitive and academic skills.
\end{abstract}

Keywords: Deaf, American Sign Language, Reading, Bilingual, Family

\section{Introduction}

Deaf readers tend to lag behind their hearing peers, with the average reading level commonly pinpointed the fourth grade (Allen, 2002; Conrad, 1979; Marschark \& Harris, 1996; Musselman, 2000). Mayer and Wells' (1996) rationale for this delay is that American Sign Language (ASL) cannot serve as the bridge to English literacy. They posit that deaf students cannot use ASL grammatical knowledge to transition between ASL and written English, because there is no written form of ASL (Mayer \& Akamatsu, 1999). Consequently, for deaf individuals who use ASL, written English cannot be directly mapped back to ASL. Others disagree, with Evans (2004) proposing that one cannot be taught English without a bridge, implicating the importance of ASL as that bridge in the instruction of English. Due to the lack of direct mapping between visual ASL and written English, deaf individuals often utilize their knowledge of ASL structure as a guide for entry to text (Evans, 1998).

With this contradictory knowledge base, there is controversy about how to teach literacy to deaf children. In contrast to the deficit model, which uses strategies developed for hearing children to teach deaf children (Perfetti \& Sandak, 2000), beginning in the late 1980's bilingual education programs were suggested as appropriate strategies for increasing deaf individuals' reading levels (Johnson, Liddell, \& Erting, 1998). Since that time, the number of bilingual programs has increased in academic settings (Bailes, 2001; Benedict \& Sass-Lehrer, 2007; Hermans, Knoors,

Authors' Note: The first author of this paper was an Undergraduate Summer Research Fellow at the NSF supported Science of Learning Center on Visual Language and Visual Learning in the summer of 2009 supported by grant number SBE-0541953. Other authors were faculty and graduate assistants involved with this Summer Research Institute. We would like to thank the participants for their help with this project.
Ormel, \& Verhoeven, 2008; Singleton, Supalla, Litchfield, \& Schley, 1998; Wilbur, 2000). Current research that focuses on bilingualism with deaf individuals highlights the use of ASL for general communication, as well as for teaching English, reading, and writing (Allen, 2002). In fact, fluent ASL-English bilinguals possess grammatically-structured ASL that serves as a bridge to the acquisition of written English (Grosjean, 2001).

However, teachers of the deaf often do not take advantage of ASL skills as a bridge to English literacy. Many do not clearly distinguish grammatical differences between ASL and English for their students, therefore missing the opportunity to teach their students how to map the grammar of one language to the grammar of a second language (Chamberlain, Morford, \& Mayberry, 2000). While hearing schoolchildren are required to take courses in English and English grammar, deaf children are not required to take ASL grammar courses and often these courses are not even offered (S. Nover, personal communication, September 28, 2009). A national formal curriculum for ASL has not been developed, even though local schools may have developed one in-house. But all too often, these in-house ASL curricula are not developed by curriculum specialists and are not research based.

Often, the deaf child is attempting to learn both basic interpersonal communicative skills (BICS) and cognitive academic language proficiency (CALP) (Cummins,1979) when they arrive at school, resulting from incomplete access to a visual language for social interactions at home and with peers during the traditional period for language acquisition. Hence, first and second language acquisition, as well as education in general, is extremely inconsistent between hearing and deaf individuals because hearing children in the United States tend to arrive at school with fully developed social language or BICS and then use this base as a scaffold into academic language or CALP. 
However, for deaf children, who often arrive at school with no (L1), no social language instruction is provided before formal academic English instruction (S. Baker, personal communication, Sept 22, 2009). While the proponents of bilingualism for deaf individuals emphasize the bilingual use and equal value of ASL and English, the equality of ASL is not always upheld, as shown by the aforementioned imbalances in language education (Evans, 1998). Rather, the comprehensive development of ASL as a first language is often not a priority in the education of deaf children.

A great deal of research supports an educational method of utilizing a well-developed first language to support and facilitate the acquisition of a second language. Native language proficiency is a strong predictor of second language skill (Hakuta, 1990). Cummins (2000; 2006) proposed the Linguistic Interdependence Theory, which proposes that competence in a second language is a function of proficiency in one's first language. When applied to deaf individuals, this research suggests that individuals who have full command of ASL as a first language are better disposed to learn English as a second language. Therefore, deaf individuals' below-average reading skills may likely stem from inadequate instruction of ASL in the educational environment, rather than the insufficient aptitude of deaf students (DeLana, Gentry, \& Andrews, 2007). Indeed, research has shown that failing to completely develop a first language results in severely negative consequences, including major challenges in academic and vocational successes (Niemann, Greenstein, \& David, 2004; Strong \& Prinz, 1997).

\section{Family Influences on Deaf Individuals}

Parental communication skill significantly predicts deaf children's positive language and academic development (Calderon, 2000). Often, deaf children do not have clear or direct access to their parents' language. In order to provide sufficient communication, parents must be attuned and responsive to their child's needs. By recognizing the importance of communication and the child's communication needs, parents can foster more positive educational outcomes. When comparing deaf children of deaf parents (DoD) and deaf children of hearing parents (DoH), research has found that DoD generally outperform DoH children in future linguistic and academic success related to their ASL abilities (Meadow, 1968; Quigley \& Frisini, 1961; Stevenson, 1964; Strong \& Prinz, 1997; Stuckless \& Birch, 1966).

Additionally, parental hearing status has been found to have an effect on ASL and English abilities, indicating that deaf parents are more likely to aid in the development of ASL (Mounty, Nover, \& Pucci, 2008). In an interview study of parents and teachers of successful deaf readers, all respondents focused on the importance of ASL as a bridge to written literacy. They emphasized the importance of adult involvement in connecting the visual language of ASL to the written language of English through shared book reading and connecting fingerspelling to corresponding written letters. Each individual emphasized the sociocultural context of educated deaf adults leading young deaf children towards literacy by exposing them to a print culture in the home.

An additional familial characteristic that may be predictive of deaf children's literacy is the family's social economic status (SES), which is often measured by maternal education level. In studies with hearing children, maternal education level has been found to be a strong predictor of children's academic success (Stevenson \& Baker, 1987). However, Calderon (2000) found that maternal education level alone did not predict deaf children's ASL and reading skills. Instead, Calderon reported that while a mother's education level was important, the quantity and quality of mother-child communication had a stronger impact on the child's academic outcome.

\section{Research Question and Hypotheses}

The goal of the current study was to investigate ASL proficiency and reading skills within a sample of deaf individuals, as well as to ascertain the impact of familial characteristics on language and literacy development. Two hypotheses were developed:

Hypothesis 1: Signing skills will correlate positively with English literacy skills.

Hypothesis 2: Family characteristics will impact bilingual skills, including parental involvement, parental communication, and maternal level of education.

\section{Method}

\section{Participants}

The current study utilized a convenience sample of 55 deaf individuals from Gallaudet University and the Washington, DC metropolitan area. Participants were recruited in two ways: the National Science Foundation's Science of Learning Center on Visual Language and Visual Learning (VL2) Volunteer Database and flyers posted on the Gallaudet University campus. Individuals recruited through the VL2 Volunteer Database were sent an invitation to participate via email, with information on how to contact the investigators. All participants from this database are current undergraduate students. Individuals recruited through flyers were provided with contact information on the advertisement, through which they could obtain scheduling information. All participants who responded to the flyer were either students, both graduate and undergraduate in a summer session, or college graduates living in the Washington, DC area.

Demographic characteristics of the sample are listed in Table 1. To be classified as a native signer, participants had to have deaf parents and report their acquisition of ASL began prior to age three. The criterion of having deaf signing parents creates the sociocultural experience of full access to a visual language by adults who understand how to guide visual attention and scaffold visual language during the critical period of language acquisition (Corina \& Singleton, 2009; Mayberry, 2007).

\section{Measures}

Data were collected using the following three measures: the VL2 Background Questionnaire, the American Sign Language - Sentence Reproduction Test (ASL-SRT) (Hauser, Paludneviciene, Supalla, \& Bavelier, 2008), and the Passage Comprehension subtest from Woodcock Johnson III Tests of Achievement (WJ III ACH) (Woodcock, McGrew, \& Mather, 2001).

The VL2 Background Questionnaire consists of 101 questions related to participants' demographic and background characteristics, including ethnicity, age, education placements, family hearing status, and level of hearing loss. This questionnaire was administered online via http://www. surveymonkey.com. 
Table 1.

Demographic characteristics of the sample $(\mathrm{N}=55)$

\begin{tabular}{|c|c|c|}
\hline \multicolumn{2}{|c|}{ Demographic Characteristic } & \multirow{2}{*}{$\begin{array}{l}\text { Percen } \\
45.5 \% \\
54.5 \%\end{array}$} \\
\hline Sex & $\begin{array}{l}\text { Men } \\
\text { Women }\end{array}$ & \\
\hline Age & $\begin{array}{l}18-25 \text { years } \\
26-30 \text { years } \\
31-43 \text { years }\end{array}$ & $\begin{array}{l}72.3 \% \\
12.8 \% \\
12.8 \%\end{array}$ \\
\hline ASL Use & $\begin{array}{l}\text { Native } \\
\text { Non-Native }\end{array}$ & $\begin{array}{l}21.8 \% \\
78.2 \%\end{array}$ \\
\hline $\begin{array}{l}\text { Educational Back- } \\
\text { ground }\end{array}$ & $\begin{array}{l}\text { Primarily Mainstream } \\
\text { Primarily Deaf Institution } \\
\text { Equal/Transfer }\end{array}$ & $\begin{array}{l}45.5 \% \\
36.3 \% \\
18.2 \%\end{array}$ \\
\hline Ethnicity & $\begin{array}{l}\text { European American } \\
\text { African American } \\
\text { Latino/Latin American } \\
\text { Pacific Islander } \\
\text { Middle Eastern } \\
\text { Other/Mixed }\end{array}$ & $\begin{array}{c}54.5 \% \\
30.9 \% \\
3.6 \% \\
3.6 \% \\
1.8 \% \\
5.5 \%\end{array}$ \\
\hline $\begin{array}{l}\text { Maternal Educational } \\
\text { Levels }\end{array}$ & $\begin{array}{l}\text { No Diploma } \\
\text { High School Diploma } \\
\text { Some College } \\
\text { BA/BS } \\
\text { Some Graduate Courses } \\
\text { MA/MS } \\
\text { Some Post-Masters Courses } \\
\text { Doctorate }\end{array}$ & $\begin{array}{c}12.7 \% \\
30.9 \% \\
21.8 \% \\
9.1 \% \\
5.5 \% \\
10.9 \% \\
1.8 \% \\
5.5 \%\end{array}$ \\
\hline
\end{tabular}

The ASL-SRT was used to evaluate each participant's ASL proficiency. The ASL-SRT is accessed using a password-protected connection to a web-based video interface located on a server at the National Technical Institute for the Deaf (NTID) in Rochester, NY. The ASL-SRT presents participants with 20 ASL sentences signed by a native signer (Hauser et al., 2008). The participant is required to view each video clip and then reproduce the sentence exactly as it was presented. The participant's reproduction is also recorded through the online video interface, and is scored by native signers at NTID in the Deaf Studies Lab headed by Peter Hauser using a 1 (sentences are reproduced exactly as signed) or 0 (one or more errors occurred in the reproduction) scoring rubric. The total range of scores is from 0 (no correct reproductions) to 20 (all reproductions were exactly as presented). These sentences progressively increase in syntactic, thematic, and morphemic complexity. Inter-rater reliability of the ASL-SRT has been reported to be $r=0.83, p<$ 0.01 (Hauser et al., 2008).

The Passage Comprehension subtest of the WJ III ACH was used to evaluate participants' written English comprehension and reading skills (Woodcock et al., 2001). The Passage Comprehension subtest requires each participant to read a short passage and identify the missing key word that is most appropriate given the context of that passage. This subtest consists of 47 items and two practice items, arranged in order of increasing difficulty measured by increasing passage lengths, more complex vocabulary, and syntactic and semantic complexity. In previous research, this subtest has been used with deaf individuals and displayed a split-half reliability of 0.91 (Easterbrooks \& Huston, 2008).

\section{Procedure}

This study was approved by the university's IRB. When participants arrived for the study, they were assigned a participant number in order to preserve anonymity. All participants were provided with an explanation of the project and explanation of informed consent in written English and ASL, and subsequently signed the informed consent form.

Participants were first administered the VL2 Background Questionnaire. After completion of the Background Questionnaire, the ASL-SRT and Passage Comprehension were alternatively administered second and third, in order to counterbalance the order of administration. On average, administration of all three measures required two hours to complete. Participants received 40 dollars to compensate them for their time and effort.

\section{Results}

All statistical analyses were performed using SPSS, with the alpha level set at 0.05 . Data screening indicated the presence of no outliers. In order to conduct analyses of bilingual ability, a "bilingual" variable was created, by transforming the ASL-SRT and the Passage Comprehension raw scores. These raw scores were converted first to Z-scores and then transformed to T-scores. Next, multiplying the two T-scores together created a combined Bilingual Ability score. Figure 1 displays a boxplot of the Bilingual Ability variable, indicating a near normal distribution.

\section{Descriptive Statistics}

Table 2 presents descriptive statistics for scores on the ASL-SRT and Passage Comprehension. With respect to the Passage Comprehension subtest, the minimum score indicates a reading grade level of 1.7 and the maximum score indicates post-college level reading. The mean Passage Comprehension score falls at the 5.8 grade level.

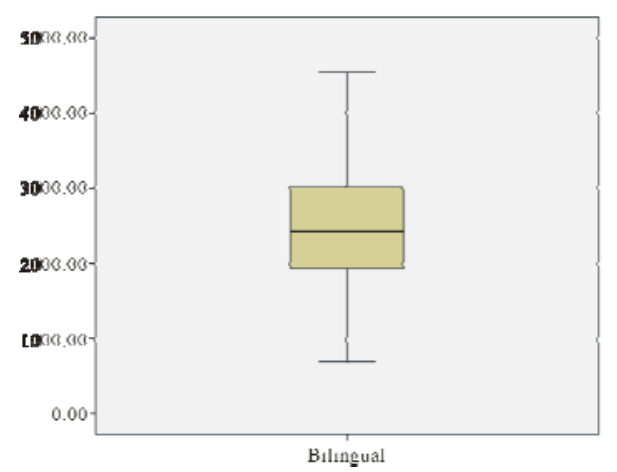

Figure 1.

Distribution of bilingual scores.

Table 2.

Descriptive statistics of ASL-SRT and passage comprehension.

\begin{tabular}{lcccc}
\hline & Min. & Max. & Mean & S.D. \\
\hline ASL-SRT & 1 & 19 & 10.70 & 4.42 \\
Passage Comprehension (raw score) & 16 & 43 & 32.49 & 5.73 \\
\hline
\end{tabular}


Hypothesis 1: Signing skills will correlate positively with English literacy skills.

A Pearson correlation was conducted to analyze the relationship between the ASL-SRT raw scores and the Passage Comprehension raw scores. A significant relationship occurred; $r(53)=0.48, p<0.001$.

Hypothesis 2: Influence of familial characteristics on bilingual abilities.

A t-test indicated that native signing of ASL was significantly related to participants' bilingual abilities, with native signers $(M=3334.51, \mathrm{SD}=618.59)$ exhibiting more proficient bilingual abilities than non-native signers $(\mathrm{M}=2327.35, \mathrm{SD}=$ 779.33), $t(53)=4.12, \mathrm{p}=0.000$. Additionally, the relationship between maternal education level and bilingual abilities was significant, with higher levels of maternal education related to more proficient bilingual abilities, $r(54)=0.521, \mathrm{p}=0.000$. Here, maternal education level was used as a proxy for family socioeconomic status, as is standard practice in demographic public health research with hearing subjects (Desai \& Alva, 1998; Stevenson \& Baker, 1987).

Regression analyses indicated that native signing and maternal education level significantly predicted Bilingual Abilities, $\mathrm{R}^{2}=0.384, \mathrm{R}_{\text {adj }}=0.347, \mathrm{~F}(3,50)=10.395, \mathrm{p}=0.000$. This model accounted for $38.4 \%$ of the variance in Bilingual Ability. A summary of the regression coefficients is presented in Table 3. Other variables that were not significant at the $p=0.05$ level (e.g., family communication mode, hearing status at birth) were dropped from the model.

\section{Discussion}

The goal of the current study was to answer two main questions. First, what is the relationship between ASL proficiency and reading skills? Second, how do family characteristics impact bilingual abilities? The first hypothesis, which predicted a significant positive relationship between a measure of ASL proficiency and a measure of reading skills, was supported. This significant finding provides some support for the idea that establishing ASL as a complete first language is related to skills in English as a second language.

In a recent study, Allen, Hwang, and Stansky (2009) found that deaf individuals' ASL scores explained $68 \%$ of the variance in reading scores. However, in the current study, only $23 \%$ of the variance in reading skill was explained by ASL ability. One possible explanation for this discrepancy is cultural differences among participants in the current sample. For example, a

Table 3.

Coefficients for model variables.

\begin{tabular}{|c|c|c|c|c|c|c|}
\hline & \multirow{2}{*}{ B } & \multirow{2}{*}{ Beta } & \multirow{2}{*}{$t$} & \multirow{2}{*}{$p$} & \multicolumn{2}{|c|}{$\begin{array}{l}\text { 95\% Confidence Inter- } \\
\text { val }\end{array}$} \\
\hline & & & & & Lower & Upper \\
\hline $\begin{array}{l}\text { Native / Non- } \\
\text { Native }\end{array}$ & -744.329 & -0.352 & -2.811 & 0.007 & -1276.135 & -212.524 \\
\hline $\begin{array}{l}\text { Maternal } \\
\text { Education }\end{array}$ & 174.087 & 0.395 & 3.331 & 0.002 & 69.105 & 279.069 \\
\hline
\end{tabular}

study conducted with the same data set found that there was no significant relationship between ASL and reading for Black deaf individuals (Myers, Clark, Musyoka, Anderson, Gilbert, Agyen, \& Hauser, In press). While this is one possible explanation for the discrepancy between the current sample and Allen et al.'s sample, further analysis is necessary to account for the discrepant strengths of the relationship between ASL proficiency and reading skill.

With respect to the second hypothesis, it was found that native signers of ASL had significantly higher bilingual abilities in ASL and written English, implying that having control of ASL as a native language may act as a bridge to stronger reading abilities. Previous research conducted by Vernon and Koh (1970), Strong and Prinz (1997), and Stuckless and Birch (1966) has shown that deaf children of deaf parents perform significantly better on reading comprehension tests than do deaf children of hearing parents. As a result, deaf children of deaf parents, who are raised in an ASL environment and develop ASL as a native language, have been found to possess stronger reading skills than deaf children raised by hearing parents, who do not develop ASL as a native language.

Additionally, in the current sample, maternal education level significantly predicted deaf children's bilingual abilities, with higher education levels corresponding to more proficient abilities in ASL and written English. Similarly, Magnuson, Sexton, Davis-Kean, and Huston (2009) found that improvements in level of maternal education were associated with improvements in hearing children's language development. Magnuson et al. suggested that mothers with higher educational levels were more interactive with their children and provided them with more learning-related materials. It was suggested that these improvements in maternal responsiveness and learning materials account for subsequent improvements in language development. Interestingly, other family variables were not significantly related to this effect.

One major limitation of the current study resulted from the difficulty of recruiting deaf native signers, as this group comprises only five percent of the deaf community (Mitchell \& Karchmer, 2004). A larger proportion of native signers from this sample were graduate students than non-native students, possibly obscuring direct comparisons between the native and nonnative groups. Future research should aim to recruit a larger number of native signers to ensure more equivalent comparisons of deaf individuals who are native and non-native signers. However, it should be noted that academic achievement and age of L1 acquisition inherently covary, as early L1 exposure is related to advantages in a number of cognitive domains (Mayberry, 2007). Therefore, it may be that native signers are inherently more likely to attend graduate school. However, more research is needed in this area. Additionally, more in-depth research is needed regarding the influence of family interaction styles and communication modes on ASL proficiency and English literacy.

While this study possesses limitations, the reported findings and implications for future research are nonetheless beneficial for the field of deaf education. Increasing research regarding language development in deaf children can lead to significant improvements in early intervention programs, parenting resources, policy-making, and the system of deaf education in the United States, all aimed at improving the literacy of deaf children. 


\section{References}

Allen, B. (2002). ASL-English bilingual classroom: The families' perspectives. Bilingual Research Journal, 26, 149-168.

Allen, T. E., Hwang, Y., \& Stansky, A. (2009). Measuring factors that predict deaf students' reading abilities: The VL2 Toolkit-Project Design and Early Findings. Paper Presented at the 2009 Annual Meeting of the Association of College Educators of the Deaf and Hard of Hearing, New Orleans.

Bailes, C. N. (2001). Integrative ASL-English language arts: Bridging paths to literacy. Sign Language Studies, 1, 147-174.

doi:10.1353/sls.2001.0002

Benedict, B. S., \& Sass-Lehrer, M. (2007). The ASL and English bilingual approach: A professional perspective. In S. Schwartz (Ed.), Choices in Deafness: A Parent's Guide to Communication Options (3rd ed., pp. 185-221). Bethesda, MD: Woodbine House.

Calderon, R. (2000). Parental involvement in deaf children's education programs as a predictor of child's language, early reading, and social emotional development. Journal of Deaf Studies and Deaf Education, 5, 140-155. doi:10.1093/deafed/5.2.140

Chamberlain, C., Morford, J. P., \& Mayberry, R. I. (2000). Language acquisition by eye. Mahwah, NJ: Lawrence Erlbaum Associates.

Conrad, R. (1979). The deaf school child: Language and function. London: Harper \& Row.

Corina, D., \& Singleton, J. (2009). Developmental social cognitive neuroscience: Insights from deafness. Child Development, 80, 952967. doi:10.1111/j.1467-8624.2009.01310.x

Cummins, J. (1979). Cognitive / academic language proficiency, linguistic interdependence, the optimum age question and some other matters. Working Papers on Bilingualism, 19, 121-129.

Cummins, J. (2000). Language, power, and pedagogy: Bilingual children in the crossfire. Buffalo, NY: Multilingual Matters.

Cummins, J. (2006,). The relationship between ASL proficiency and English academic development: A review of the research. Paper Presented at the Workshop Challenges, Opportunities, and Choices in Education Minority Group Students, Hamar University College, Norway.

DeLana, M., Gentry, M. A., \& Andrews, J. (2007). The efficacy of ASL / English bilingual education: Considering public schools. American Annals of the Deaf, 152, 73-87. doi:10.1353/aad.2007.0010

Desai, S., \& Alva, S. (1998). Maternal education and child health: Is there a strong casual relationship? Demography, 35, 71-81. doi:10.2307/3004028

Easterbrooks, S., \& Huston, S. (2008). Signed Reading fluency of students who are deaf/hard of hearing. Journal of Deaf Studies and Deaf Education, 13, 37-54. doi:10.1093/deafed/enm030

Evans, C. J. (1998). Literacy acquisition in deaf children. Paper Presented at Annual Meeting of the Teachers of English to Speakers of Other Language, Seattle, WA.

Evans, C. J. (2004). Literacy development in deaf students: Case studies in bilingual teaching and learning. American Annals of the Deaf, 149, 17-27. doi:10.1353/aad.2004.0011

Grosjean, F. (2001). The right of the deaf child to grow up bilingual. Washington, DC: Gallaudet University Press.

Hakuta, K. (1990). Bilingualism and bilingual education: A research perspective. Occasional Papers Series, No. 1. Washington, DC: National Clearinghouse for Bilingual Education.

Hauser, P., Paludneviciene, R., Supalla, T., \& Bavelier, D. (2008). American Sign Language - Sentence Reproduction Test: Development \& implications. In R. M. de Quadros (Ed.), Sign languages: spinning and unraveling the past, present, and future. Petrópolis, Brazil: Editora Arara Azul.

Hermans, D., Knoors, H., Ormel, E., \& Verhoeven, L. (2008). The relationship between the reading and signing skills of deaf children in bilingual education programs. Journal of Deaf Studies and Deaf Education, 13, 518-530. doi:10.1093/deafed/enn009

Johnson, R. E., Liddell, S. K., \& Erting, C. J. (1998). Unlocking the curriculum: Principles for achieving access in deaf education. Gal- laudet Research Institute Working Paper, 89, Washington, DC: Gallaudet University Press.

Magnuson, K., Sexton, H., Davis-Kean, P., \& Huston, A. (2009). Increases in maternal education and young children's language skills. Merrill - Palmer Quarterly, 55, 319-350.

Marschark, M., \& Harris, M. (1996). Success and failure in learning to read: The special case of deaf children. In C. Coronoldi, \& J. Oakhill (Eds.), Reading Comprehension Difficulties: Process and Intervention. Hillsdale, NJ: Lawrence Erlbaum.

Mayberry, R. I. (2007). When timing is everything: Age of first-language acquisition effects on second-language learning. Applied Psycholinguistics, 28, 537-549. doi:10.1017/S0142716407070294

Mayer, C., \& Akamatsu, C. (1999). Bilingual-bicultural models of literacy education for deaf students: considering the claims. Journal of Deaf Studies and Deaf Education, 4, 1-8. doi:10.1093/deafed/4.1.1

Mayer, C., \& Wells, G. (1996). Can the linguistic interdependence theory support a bilingual-bicultural model of literacy education for deaf students? Journal of Deaf Studies and Deaf Education, 1 , 93-107.

Meadow, K. (1968). Early manual communication in relation to the deaf child's intellectual, social, and communicative functioning. American Annals of the Deaf, 113, 29-41.

Mitchell, R. E., \& Karchmer, M. A. (2004). When parents are deaf versus hard of hearing: patterns of sign use and school placement of deaf and hard-of-hearing children. Journal of Deaf Studies and Deaf Education, 9, 133-152. doi:10.1093/deafed/enh017

Mounty, J., Nover, S. M., \& Pucci, C. (2008). How deaf children become proficient readers: A sociocultural perspective. Presented at the Association of College Educators - Deaf and Hard of Hearing, New Orleans, LA.

Musselman, C. (2000). How do children who can't hear learn to read an alphabetic script? A review of the literature on reading and deafness. Journal of Deaf Studies and Deaf Education, 5, 9-31. doi:10.1093/deafed/5.1.9

Myers, C., Clark, M. D., Musyoka, M. M., Anderson, M. L., Gilbert, G. L., Agyen, S., \& Hauser, P. C. (in press). The interaction of culture, family characteristics, reading experiences, language, and educational level: Impacts on Black Deaf individuals' reading skills. American Annals of the Deaf.

Niemann, S., Greenstein, D., \& David, D. (2004). Helping children who are deaf: Family and community support for children who do not hear well (Early assistance series for children with disabilities). $\mathrm{Pa}$ laestra, 21, 52-53.

Perfetti, C. A., \& Sandak, R. (2000). Reading optimally builds on spoken language: Implications for deaf readers. Journal of Deaf Studies and Deaf Education, 5, 32-50. doi:10.1093/deafed/5.1.32

Quigley, S., \& Frisina, R. (1961). Institutionalization and PsychoEducational Development of Deaf Children. CEC Research Monograph. Washington, D.C.: Council on Exceptional Children.

Singleton, J. L., Supalla, S., Litchfield, S., \& Schley, S. (1998). From sign to word: Considering modality constraints in ASL / English bilingual education. Topics in Language Disorders, 18, 16-29.

Stevenson, D. L., \& Baker, D. P. (1987). The family-school relation and the child's school performance. Child Development: Special Issue: Schools and Development, 58, 1348-1357.

Stevenson, E. (1964). A study of the educational achievement of deaf children of deaf parents. California News, 80, 143.

Strong, M., \& Prinz, P. (1997). A study of the relationship between American Sign Language and English literacy. Journal of Deaf Studies and Deaf Education, 2, 37-46.

Stuckless, R., \& Birch, J. (1966). The influence of early manual communication on the linguistic development of deaf children. American Annals of the Deaf, 106, 436-480.

Vernon, M., \& Koh, S. D. (1970). Early manual communication and deaf children's achievements. American Annals of the Deaf, 115, 527-536.

Wilbur, R. B. (2000). The use of ASL to support the development of English and literacy. Journal of Deaf Studies and Deaf Education, 5, 
81-104. doi:10.1093/deafed/5.1.81

Woodcock, R. W., McGrew, K. S., \& Mather, N. (2001). Woodcock-
Johnson Test of Achievement. Rolling Meadows, IL: Riverside Publishing. 